\title{
Combination of Esterified Kraft Lignin and MAPE as Coupling Agent for Bark/HDPE Composites
}

\author{
Nicolas Mariotti ${ }^{1}$, Xiang-Ming Wang ${ }^{2}$, Denis Rodrigue ${ }^{3} \&$ Tatjana Stevanovic $^{1}$ \\ ${ }^{1}$ Research center on renewable materials (CRMR), Department of wood science and forestry, 2425 rue de la \\ terrasse, Université Laval, Quebec, QC, Canada \\ ${ }^{2}$ FPInnovations, 319 rue Franquet, Quebec, QC, Canada \\ ${ }^{3}$ Research center for advanced materials (CERMA), Department of chemical engineering, 1065 Avenue de la \\ médecine, Université Laval, Quebec, QC, Canada \\ Correspondence: Tatjana Stevanovic, Department of wood science and forestry, Université Laval, Quebec, QC, \\ G1V 0A6, Canada. Tel: 1-418-656-2131 (7337).E-mail: tatjana.stevanovic@sbf.ulaval.ca
}

Received: November 23, $2013 \quad$ Accepted: December 23, $2013 \quad$ Online Published: January 23, 2014
$\begin{aligned} & \text { doi:10.5539/jmsr.v3n2p8 } \\ & \text { URL: http://dx.doi.org/10.5539/jmsr.v3n2p8 }\end{aligned}$

\begin{abstract}
Refined black spruce bark fibers and high density polyethylene (HDPE) were used to produce wood plastic composites (WPC) while exploring for the first time the potential of using esterified Kraft lignin as a coupling agent. Two types of lignin esterification (succinic acid and maleic acid anhydrides) were examined alone or in combination with maleated polyethylene (MAPE), and compared with a commercial coupling agent: maleated polyethylene (MAPE). Three contents of coupling agents $(2 \% ; 5 \% ; 10 \%$ by weight) were considered for esterified lignin and three combinations of lignin and MAPE (100:0; 50:50; 0:100), while bark fibers content was kept constant at 30\%. Morphological (scanning electron microscopy - energy dispersive X-ray spectroscopy [SEM-EDS]), thermal (thermogravimetric analysis [TGA] and differential scanning calorimetry [DSC]) and mechanical properties (tensile and flexural) of the composites were measured. Two optimum formulations were determined based on the best bark-matrix interface leading to highest mechanical properties: an equal content of maleic acid anhydride esterified lignin and MAPE at 5\%, or an equal content of succinic esterified lignin and MAPE at $2 \%$.
\end{abstract}

Keywords: refined black spruce bark fibers, high density polyethylene (HDPE), wood plastic composites (WPC), coupling agent: maleic anhydride grafted polyethylene (MAPE), maleic and succinic esterified kraft lignins, thermal and mechanical properties, scanning electron microscopy [SEM] - energy dispersive X-ray spectroscopy [EDS] (SEM-EDS)

\section{Introduction}

It is a common consent now among research scholars, scientific institutions, industries, research and development centers, as well as governments, that there is a real need for intensification of activities enabling the development of materials containing polymers derived from renewable resources. The simple introduction of renewable resources into synthetic polymer matrices offers a myriad of combinations due to the variety of structures available from nature. However, as noted by Gandini (2008), one should not base a naive optimism merely on multiple possibilities of combination between different polymers available and high diversity of exploitable natural fibers. Some specific combinations will definitely be of low interest, while others will answer the diverse needs of the world's growing population and therefore gradually replace current synthetic products, bringing an economic impact while being eco-friendly for our society.

Most of the residues from the pulp and paper or wood product industries remain underexploited, despite important research efforts made to develop new products or uses. For decades, wood has been introduced as a filler to increase stiffness and strength of polyolefin-based biosourced composites, known as wood plastic composites (WPC) (Lu, Wu, \& McNabb, 2000; Colom, Carrasco, Pagès, \& Cañavate, 2003). The main difficulty in developing good properties resides in the different chemical properties between hydrophobic polyolefin matrices and hydrophilic wood fibers, resulting in poor compatibility. In order to improve the interaction between a polyolefin matrix and lignocellulosic fibers, a coupling agent is generally required. Polar functionality 
and molecular weight of coupling agent are optimized to provide a good interface between the matrix and reinforcements or fillers such as glass, wood fibers, minerals, metals or bark fibers. Over the years, maleic anhydride grafted polyethylene (MAPE) has been shown to be a good material to link natural fibers with polyethylene, as improved mechanical properties of the resulting WPC were obtained (Gandini, 2008; Lu et al., 2000; Colom et al., 2003). This favourable effect is attributed to the capacity of MAPE to form hydrogen (or covalent) bonds with lignocellulosic fillers to obtain good compatibility and adhesion with the matrix.

Lignocellulosic renewable materials are generally less abrasive compared to inorganic fillers resulting in a more sustainable process life of the equipment. Recently, some studies focused on the manufacture of bio-sourced composites based on polyolefin matrices in order to demonstrate the potential of bark particles to act as filler in WPC (Sewda \& Maiti, 2007; Ngueho-Yemele et al., 2013). The incorporation of natural fibers may improve thermal stability of the polymer materials (Sewda \& Maiti, 2007; Ngueho-Yemele, Koubaa, Cloutier, Soulounganga, \& Wolcott, 2010). Ngueho-Yemele et al. (2013) studied the impact of hot water extraction of black spruce bark particles before incorporation in high density polyethylene (HDPE). On the other hand, interesting chemical composition of the water extracts of black spruce bark qualifies them for pharmacological or alimentary applications (García-Pérez, Royer, Desjardins, Pouliot, \& Stevanovic, 2012), while leaving extracted bark fibers available for their conventional applications as fiber sources or energy production. Large quantities of bark produced in Quebec are presently almost entirely used for thermal energy production (Ministère des ressources naturelles et de la faune du Québec, 2007). Numerous research efforts have been made to use bark for high value-added products, for example as an alternative source of fibers for particleboard and medium density fiberboard manufacturing (Xing, Deng, \& Zhang, 2007; Gupta, 2009; Gao, Wang, Wan, \& Brunette, 2011).

Lignins are the third most available natural polymers and their structures depend on plant origin and extraction process. They are the most abundant aromatic polymers on earth, and their content varies on average between $20 \%$ and $35 \%$ depending on plant origin (Stevanovic \& Perrin, 2009). Recently, it has been demonstrated that Kraft lignins could be precipitated from residual black liquor without negatively affecting the Kraft process (Tomani, 2009). Significant amounts of Kraft lignin could become available using the LignoBoost $\odot$ patented process developed in Sweden (Tomani, 2009). Kraft pulp mills could thus maintain the same pulp production capacity, while precipitating a portion of lignin from black liquor. It is estimated that in Quebec, 130,000 tons of black liquor could be used for lignin precipitation annually, without disturbing mill production (FPInnovations \& Ressource Naturelle et faune du Québec, 2009). On the other hand, environmental problems are related to carbon dioxide emissions. Inside a pulp and paper Kraft industry, a source of 0.166 tons of $\mathrm{CO}_{2}$ per ton of produced pulp is available at the lime kiln stage (Manning \& Tran, 2010). Kraft lignin can be precipitated from black liquor following the procedure proposed by LignoBoost (Nagy, Kosa, Theliander, \& Ragauskas, 2009; Schorr, Diouf, \& Stevanovic, 2013), which explored the possibility to use this source of $\mathrm{CO}_{2}$ from the process itself. A protocol inspired by the same process was applied for lignin precipitation in this research.

This work presents an original integration of the concept of bio-refinery via the use of Kraft lignin in combination with black spruce bark (Picea mariana) fibers to produce WPC based on high density polyethylene. The general objective of the study was to investigate the potential of esterified Kraft lignins, alone or in combination with maleated polyethylene, to act as a coupling agent between high density polyethylene and black spruce bark fibers. The effect of esterified lignin addition on flexural and tensile properties of HDPE composites containing bark fibers were studied in comparison with composites made with a commercial coupling agent (MAPE).

\section{Experimental}

\subsection{Materials}

High density polyethylene was used as the polymer matrix. ExxonMobil HD 6605 (Exxon Chemicals) has a melt flow index of $5 \mathrm{~g} / 10 \mathrm{~min}$ (ASTM D 1238 at $190{ }^{\circ} \mathrm{C}$ and $2.16 \mathrm{~kg}$ ) and a density of $948 \mathrm{~kg} / \mathrm{m}^{3}$. A commercial coupling agent, Epolene C-26, was used as a base of comparison. This polyethylene grafted with maleic anhydride (MAPE) has an acid number of $8(\mathrm{mg} \mathrm{KOH} / \mathrm{g}$ ) and a molecular weight of 65,000 g/mol (Westlake Chemicals Corporation). Refined black spruce bark (Picea mariana) fibers were obtained from FPInnovations (Quebec, Canada). The raw bark samples were obtained from Scierie Leduc sawmill (Quebec, Canada). After removing the contaminants by sieving at 10 mesh, bark was conditioned and refined with an Andritz disk refiner at the FPInnovations' MDF pilot plant as specified in Fang, Deng, and Zhang (2010) and Gao et al. (2011). The refining parameters used to obtain bark fibers included steam pressure of 12 bars, plate distance of $0.1 \mathrm{~mm}$, plate speed of $2200 \mathrm{rpm}$ and retention time of $3.5 \mathrm{~min}$ at $189^{\circ} \mathrm{C}$. No wax or resin was added during refining and bark 
fibers did not contain any wood. The size distribution of bark fibers was investigated with a fiber quality analyzer (Fiber Quality Analyzer Code LDA02 from OpTest Equipment Inc.). The anhydrous density of bark was determined by a gas (nitrogen) pycnometer, ULTRAPYC 1200e (Quantachrome Instruments) and cellulose content was determined by the Kurschner and Hoffner method (Browning, 1967). Lignin content was determined by an alternative non-standard method for Klason lignin (ASTM D1106), modified by the integration of an autoclave Stevanovic (2011). Pentosans content was determined following protocols developed in our laboratory Stevanovic (2011). Determination of ash content was based on ASTM D1102 using a muffle furnace. For extractives content determination, bark fibers were extracted with water, a mixture of anhydrous ethanol:toluene (40:60) and sodium hydroxide $(\mathrm{NaOH} 1 \%)$ as specified in ASTM D1109. Three quantitative extractions were performed to determine the extractives content in each solvent.

\subsection{Precipitation and Esterification of Lignin}

Black liquor from a pulp and paper industry (Kruger Wayagamack, Quebec) containing a mixture of softwood species (black spruce/balsam fir/jack pine) was used to precipitate lignin. Carbon dioxide was used to precipitate lignin by decreasing the $\mathrm{pH}$ of black liquor from 13-14 to 8-9 following the procedure inspired by the LignoBoost process (Tomani, 2009; Wallmo \& Theliander, 2009; Öhman, Theliander, Tomani, \& Axegard, 2006) A purification step consisted of washing lignin with sulfuric acid and then with distilled water. The precipitated lignin was dried in a vacuum oven at $60{ }^{\circ} \mathrm{C}$ overnight before esterification. The esterification protocol with maleic or succinic anhydride was optimized as presented in a previous report by Stevanovic, Rodrigue, Diouf, Schorr, and $\mathrm{Hu}(2012)$.

\subsection{Composites Compounding}

An internal batch mixer (Haake Büchler Rheomix) was used to prepare WPC containing black spruce bark fibers. The fibers were dried at $80{ }^{\circ} \mathrm{C}$ overnight before processing. Three mixtures were prepared for each WPC formulation. A rotational speed of $60 \mathrm{rpm}$ was set to minimize mechanical shearing effect on the natural fibers. The mixture was kept at a temperature of $160{ }^{\circ} \mathrm{C}$ for 9 minutes in order to minimize material degradation (thermo-oxidation), and to obtain homogeneous materials. The following protocol was applied for each batch: at $\mathrm{t}_{0}$ HDPE was incorporated and melted while mixing; after three minutes the coupling agent was added (esterified lignin and/or MAPE) while continuous mixing was applied to distribute it evenly. Finally, after four minutes from the start, black spruce bark fibers were incorporated and mixing was performed for another five minutes (nine minutes total). In order to obtain WPC plates, the compounds were compression moulded in a laboratory Carver press at $175^{\circ} \mathrm{C}$ with a force of 3 tons for 5 minutes in a mould with dimensions of $115 \mathrm{~mm} \times 115 \mathrm{~mm} \times$ $2.7 \mathrm{~mm}$. The resulting plates were cut into standard dimensions for further characterizations.

\subsection{Thermal Characterizations}

Thermogravimetric (TG) measurements were performed by heating around $30 \mathrm{mg}$ of material between 50 and $900{ }^{\circ} \mathrm{C}$ in a platinum cell using a heating rate of $10^{\circ} \mathrm{C} \cdot \mathrm{min}^{-1}$. The analyzer was a model Q5000IR from TA Instruments. The samples were placed in a high quality nitrogen (99.5\% nitrogen) atmosphere with a flow rate of $50 \mathrm{~mL} \cdot \mathrm{min}^{-1}$. The software TA Universal Analysis was used to calculate the first derivative (DTG) and obtain the temperature of maximum degradation rates (DTG max). Thermal stability was characterized by the starting decomposition temperature calculated as the temperature at which $5 \%$ mass loss was produced. The solid residues at $900{ }^{\circ} \mathrm{C}$ were also determined. Differential scanning calorimetry (DSC 822e Mettler Toledo) measurements were performed on $15 \mathrm{mg}$ samples under a nitrogen atmosphere. STARe Thermal Analysis Software 9.01 was used to calculate enthalpies and crystallinity.

\subsection{Scanning Electron Microscopy (SEM) Coupled With Energy Dispersive X-Ray Spectroscopy (EDS)}

A $J E O L J S M-840 A$ scanning electron microscope was used for morphological characterizations. Each WPC sample was broken using liquid nitrogen to expose the internal structure and obtain a clean surface for scanning. To allow observation, the surface was coated with a gold/palladium alloy under low pressure and observation was made at $15 \mathrm{kV}$ using different magnifications. Interaction of the primary beam with atoms in the sample causes shell transitions which result in the emission of an X-ray. The energy dispersive X-ray spectroscopy (EDS) analysis module emits X-ray having energy characteristics of each element. The detection and measurement of the energy permit elemental analysis with a detection limit of $1 \%$. EDS can also provide qualitative analysis of elemental composition of the selected area on SEM observations. It is important to notice that no detection of the element below carbon $(\mathrm{C})$ is available using this equipment, so hydrogen $(\mathrm{H})$ is not observable. This module is used to identify each component in a WPC. 


\subsection{Physical and Mechanical Testing}

Density of bark fibers and composites was determined by a gas pycnometer, ULTRAPYC 1200e from Quantachrome Instruments, using nitrogen as the gas phase. The results were reported as the average of five measurements with standard deviation. Flexural (modulus of elasticity, MOE) and tensile properties, including modulus of elasticity, stress at break and strain at break, were determined. Three-point bending tests were performed according to ASTM D790 on samples having $80.0 \times 12.8 \times 2.5 \mathrm{~mm}^{3}$ dimensions with a support span of $60 \mathrm{~mm}$ at a cross-head speed of $10 \mathrm{~mm} / \mathrm{min}$. ASTM D 638 was used to perform tensile measurements on type $\mathrm{V}$ specimen. In each case, six repetitions per formulation were done using aa universal mechanical tester model 5565 (Instron, USA) with a $50 \mathrm{~N}$ (flexural) or $500 \mathrm{~N}$ (tensile) load cell.

\subsection{Statistical Analyses}

Experiments were conducted according to a D-Optimal design (Table 1). The factors studied included two lignin modifications (esterified with maleic or succinic anhydride) compared to MAPE, three levels of coupling agent content $(2,5$, and $10 \%)$, and three compositions of coupling agent (CA) (100\% modified lignin, $100 \%$ MAPE and 50:50 lignin:MAPE). Thus, 12 combinations with three replicates were produced, for a total of 36 compounds. Three control blends without bark fibers were also manufactured under the same conditions. Statistical Analysis System (SAS) 9.3 was used for the statistical analysis. An analysis of variance (ANOVA) was performed on this experimental plan (three factors for 12 treatments). A control with neat HDPE and a reference of WPC containing bark fibers without any coupling agent were used to discuss the results. Contrasts were performed to determine interactions between the factors studied. Finally, comparisons between treatments were performed following the Duncan method to determine the best formulation(s).

Table 1. Bark-HDPE WPC formulations: Design of experiment from D-Optimal in SAS 9.3

\begin{tabular}{llll}
\hline Coding & $\begin{array}{l}\text { Coupling agent (CA) } \\
(\text { wt \%) }\end{array}$ & CA content (wt \%) & $\begin{array}{l}\text { CA composition } \\
\text { (Lignin:MAPE) }\end{array}$ \\
\hline $\mathrm{a}$ & Succinic & 2 & $100: 00$ \\
$\mathrm{~b}$ & Succinic & 5 & $100: 00$ \\
$\mathrm{c}$ & Succinic & 10 & $100: 00$ \\
$\mathrm{~d}$ & MAPE & 2 & $00: 100$ \\
$\mathrm{e}$ & MAPE & 5 & $00: 100$ \\
$\mathrm{f}$ & MAPE & 10 & $00: 100$ \\
$\mathrm{~g}$ & Succinic + MAPE & 2 & $50: 50$ \\
$\mathrm{~h}$ & Succinic + MAPE & 5 & $50: 50$ \\
$\mathrm{i}$ & Succinic + MAPE & 10 & $50: 50$ \\
$\mathrm{j}$ & Maleic + MAPE & 5 & $50: 50$ \\
$\mathrm{k}$ & Maleic & 5 & $100: 00$ \\
\hline$l$ & $30 \%$ bark without any coupling agent \\
$m$ & HDPE & \\
\hline
\end{tabular}

\section{Results and Discussion}

\subsection{Black Spruce Fibers Characteristics}

It is well known that natural fibers are characterized by an important variability of their chemical and physical properties (Table 2). Nevertheless, the results obtained in this study are similar to those published in the literature for black spruce bark (Ngueho-Yemele et al., 2010), with somewhat lower cellulose and hemicellulose contents, which could be explained by the fact that bark was refined prior to chemical analyses, while the literature results reported untreated bark. Indeed, the Andritz disk refiner used at an elevated temperature could cause some hemicellulose (pentosan) losses. The anhydrous density (Table 2) of the bark determined by a volumetric method was $639 \mathrm{~kg} / \mathrm{m}^{3}$ for black spruce bark. (Ngueho-Yemele et al., 2010), but this technique gives the apparent bulk density without taking the porosity of the studied material into account. Here, a gas pycnometer with nitrogen 
was applied to measure density and the obtained results correspond to the density of the cell walls (Kellogg \& Wangaard, 1969; Zauer, Pfriem, \& Wagenführ, 2013). Fiber sizes determined by the fiber quality analyzer (FQA) are presented in Table 2 and aspect ratios (L/D) were found to be comparable to the findings of Ngueho-Yemele et al. (2010, 2013), while the main difference found in the average fiber length between both studies could be again attributed to the use of the disk refiner which separated longer fibers. Differences in hemicellulose content and FQA properties can explain physical and mechanical properties as indicated by Bouafif, Koubaa, Perré, and Cloutier (2009) who showed that increasing fiber size improved strength, but reduced elongation at break.

Table 2. Properties of black spruce refined bark

\begin{tabular}{|c|c|c|c|c|c|c|c|}
\hline \multicolumn{5}{|c|}{ Chemical composition $^{\mathrm{a}}(\%)$} & \multicolumn{3}{|c|}{ Extractives $(\%)$} \\
\hline & Cellulose $^{\mathrm{b}}$ & Lignin $^{c}$ & Pentosan $^{\mathrm{b}}$ & $\mathrm{Ash}^{\mathrm{d}}$ & Hot Water & Organic $^{*}$ & Inorganic $^{* *}$ \\
\hline Value & 47.3 & 43.6 & 7.5 & 1.9 & 12.7 & 7.8 & 18.9 \\
\hline \multirow[t]{3}{*}{ (SD) } & $(4.0)$ & $(3.2)$ & $(0.8)$ & $(0.1)$ & $(0.9)$ & $(0.6)$ & (1.4) \\
\hline & \multicolumn{4}{|c|}{ Physical properties } & & & \\
\hline & $\begin{array}{l}\text { Density } \\
\left(\mathrm{kg} / \mathrm{m}^{3}\right)\end{array}$ & $\begin{array}{l}\mathrm{L} \\
(\mathrm{mm})\end{array}$ & $\begin{array}{l}\mathrm{D} \\
(\mu \mathrm{m})\end{array}$ & $\begin{array}{l}\text { Aspect ratio } \\
\text { (L/D) }\end{array}$ & & & \\
\hline Value & 1557 & 1.02 & 37.8 & 10.9 & & & \\
\hline (SD) & $(28)$ & $(0.05)$ & $(1.8)$ & $(1.7)$ & & & \\
\hline
\end{tabular}

${ }^{\mathrm{a}}$ : $\quad$ Calculation based on anhydrous mass of bark

${ }^{\mathrm{b}}$ : $\quad$ On extracted fibers with toluene, ethanol and boiling water

${ }^{\mathrm{c}}$ : $\quad$ On extracted fibers with ethanol, boiling water and sodium hydroxide (1\%)

d: $\quad$ On non-extracted fibers

*: $\quad$ With ethanol-toluene mixture

**: $\quad$ With sodium hydroxide (1\%)

Table 3. TGA and DTG results for each formulation (Letter a to $\mathrm{k}$ refer to the formulation given in Table 1)

\begin{tabular}{llll}
\hline Sample & $\begin{array}{l}\text { Starting decomposition } \\
\text { temperature }\left({ }^{\circ} \mathrm{C}\right)\end{array}$ & $\begin{array}{l}\text { DTG max } \\
\left({ }^{\circ} \mathrm{C}\right)\end{array}$ & $\begin{array}{l}\text { Residues } \\
900{ }^{\circ} \mathrm{C}(\%)\end{array}$ \\
\hline $\mathrm{a}$ & 271 & 450 & 1.0 \\
$\mathrm{~b}$ & 306 & 457 & 0.5 \\
$\mathrm{c}$ & 263 & 454 & 1.5 \\
$\mathrm{~d}$ & 274 & 449 & 0.7 \\
$\mathrm{e}$ & 275 & 451 & 0.8 \\
$\mathrm{f}$ & 304 & 447 & 0.5 \\
$\mathrm{~g}$ & 298 & 450 & 0.6 \\
$\mathrm{~h}$ & 283 & 457 & 0.8 \\
$\mathrm{i}$ & 261 & 452 & 0.3 \\
$\mathrm{j}$ & 271 & 454 & 0.9 \\
$\mathrm{k}$ & 269 & 446 & 0.9 \\
\hline
\end{tabular}

\subsection{Thermal Stability (TGA Results)}

Several steps of mass loss can be observed on the thermal analysis curves, as was previously found for HDPE composites with bark (Ngueho-Yemele et al., 2010). An initial mass loss observed below $120{ }^{\circ} \mathrm{C}$ is attributed to the gradual evaporation of water and of some volatile compounds. A second mass loss observed between 200 and 
$400{ }^{\circ} \mathrm{C}$ is due to the decomposition of lignocellulosic constituents, namely hemicelluloses (around $250{ }^{\circ} \mathrm{C}$ and $300{ }^{\circ} \mathrm{C}$ ), cellulose (around $350-365^{\circ} \mathrm{C}$ ), lignin (between 270 and $410{ }^{\circ} \mathrm{C}$ as proved by Stevanovic et al., 2012), and finally HDPE (at $450{ }^{\circ} \mathrm{C}$ ) (Ngueho-Yemele et al., 2010). The results obtained for starting decomposition temperature, temperature of maximum degradation rates (DTG max), and solid residues at $900{ }^{\circ} \mathrm{C}$ are presented in Table 3. These results indicate the influence of natural fibers on WPC thermal degradation which starts around $260-300^{\circ} \mathrm{C}$ due to poor thermal stability of hemicelluloses from black spruce fibers. Temperature of maximum degradation rates for all the formulations are above $450{ }^{\circ} \mathrm{C}$ corresponding to HDPE as the major component (70\%). Solid residues at $900{ }^{\circ} \mathrm{C}$ were low (about $1 \%$ ) indicating a potential of energy recovery by combustion, useful at the end of life cycle.

\subsection{Scanning Electron Microscopy (SEM) Coupled to Energy Dispersive X-Ray Spectroscopy (EDS)}

Before analyzing the interface between bark fibers and HDPE matrix, it is important to recognize each component in the WPC. In this work, three different components are present in the composites: HDPE, black spruce bark fibers and esterified Kraft lignin. It is impossible to observe the difference between HDPE and MAPE since both are mainly composed of $\mathrm{H}$ and $\mathrm{C}$, and the oxygen content in MAPE (less than 1\%) is below the detection limit of the instrument. To well recognize each component, not only by their morphological appearance, chemical differences between them should be exploited. HDPE is based on H and C atoms, with a formula $\left(\mathrm{C}_{2} \mathrm{H}_{4}\right)_{n} \mathrm{H}_{2}$ compared to bark fibers composed of $\mathrm{H}, \mathrm{C}$ and $\mathrm{O}$. Therefore, they can be distinguished by SEM-EDS. The characteristic presence of $\mathrm{S}$ atom in Kraft lignin, which is not the case with native lignin, helps distinguish between the fibers and esterified Kraft lignin. The problems are that SEM-EDS has a detection limit of $1 \%$ and the sulfur $(\mathrm{S})$ peak is very close to the peaks of gold $(\mathrm{Au})$ and palladium $(\mathrm{Pd})$ which are used for surface coating. Theoretically, it would be possible to observe the esterified Kraft lignin due to its $\mathrm{S}$ content, because the first gold peak will become larger and the peak of the sulfur atom will appear if enough $\mathrm{S}$ content is detected. The observations in SEM coupled to energy dispersive X-ray spectroscopy (EDS), as presented in Figure 1, show the chemical distinction of each component which helped to relate the morphological appearance to the chemical distinction of each component. In Figures 1 a1) and a2), the HDPE matrix with smooth surface was analyzed (the examined area is indicated by the square) and confirmed by SEM-EDS. Typical morphology of this component was confirmed by chemical compositions based only on $\mathrm{C}$ atoms. In Figures $1 \mathrm{~b} 1$ ) and b2), the presence of $\mathrm{O}$ atoms proved that it is related to black spruce bark fiber, a raw material recognized by tracheids with bordered pits clearly visible on SEM, morphologically very different from the matrix. Finally in Figures 1 c1) and c2), esterified lignin was characterized by the presence of S atoms (on EDS), which proved that it is esterified Kraft lignin with a very porous aspect probably due to esterification.
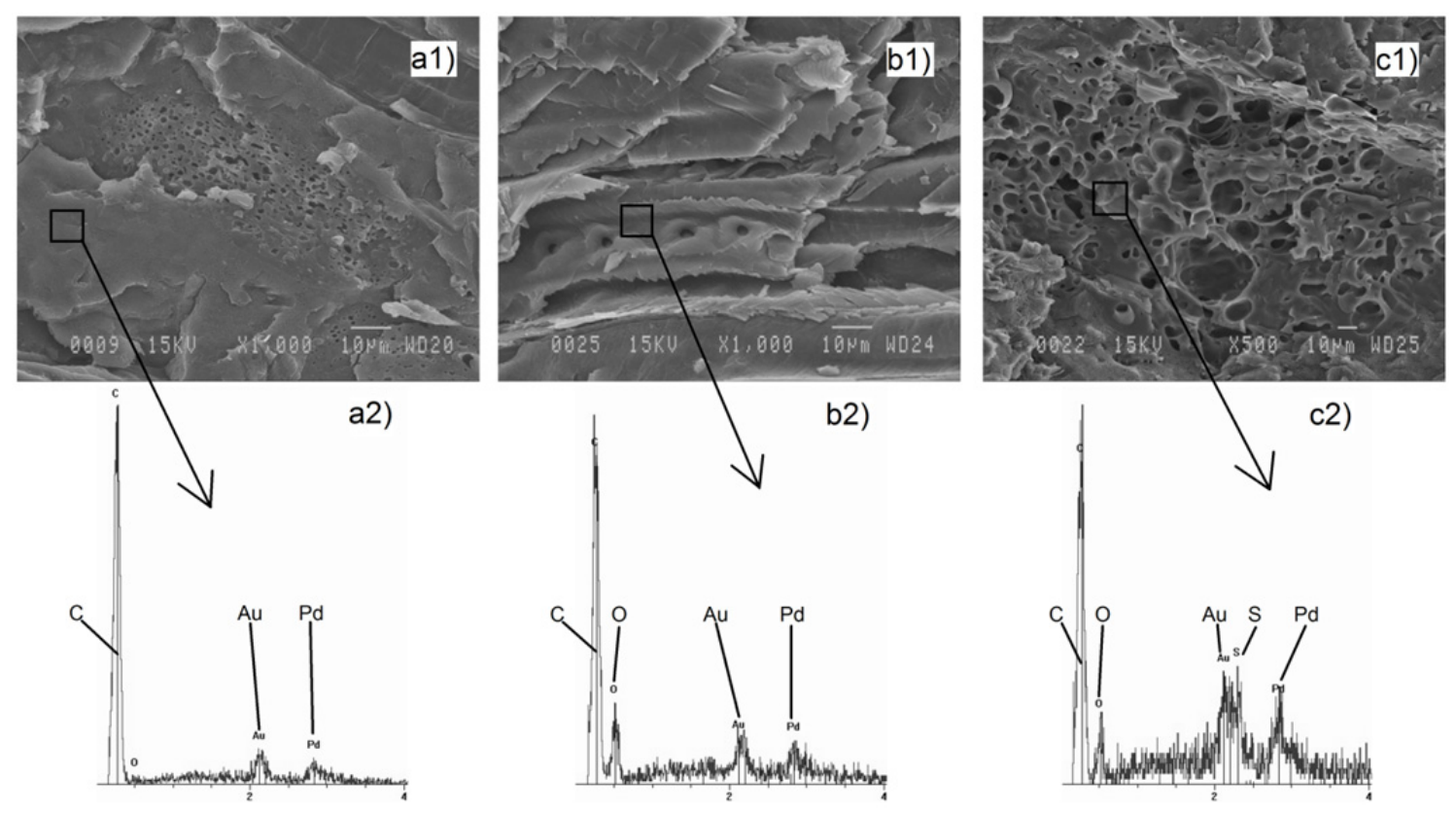

Figure 1. SEM observations (top row) coupled with EDS analyses (bottom row) to identify each component of the WPC: a1) and a2) HDPE; b1) and b2) bark fibers; c1) and c2) esterified Kraft lignin. The square indicates the analyzed area (EDS) 


\subsection{Scanning Electron Microscopy (SEM) Observations of the Bark Fiber-HDPE Matrix Interface}

Scanning electron micrographs were used to investigate the interface quality between black spruce bark fiber, esterified lignin, MAPE and HDPE, in a similar way as reported by Colom et al. (2003) and Ramezani Kakroodi, Kazemi, and Rodrigue (2013). Figure 2 shows micrographs from the fractured surfaces of the composites containing black spruce fibers (at 30\%) and their composition (a to $\mathrm{k}$ ) is presented in Table 1. These representative formulations were examined to understand the effect of coupling agent (MAPE, esterified lignin, or combination of lignin and MAPE) on interfacial adhesion between the polyolefin matrix and black spruce bark fiber. Composites having poor matrix-fiber interaction would not be able to support a significant part of the load and have weaker mechanical properties (Ramezani Kakroodi et al., 2013). The differentiation between morphological appearance of each component (lignin, HDPE or black spruce fiber) was based on the results presented in Figure 1.

\subsubsection{Esterified Kraft Lignin as Coupling Agent}

SEM micrographs of the formulations containing esterified Kraft lignin as coupling agent are shown in Figures $2 a, 2 b$, and $2 c$ for succinic esterified lignin and in Figure $2 \mathrm{k}$ for maleic esterified lignin. The references with MAPE as coupling agent are presented in Figures $2 \mathrm{~d}, 2 \mathrm{e}$, and $2 \mathrm{f}$. Weak adhesions between black spruce bark and HDPE can be seen for all contents of succinic esterified Kraft lignin (i.e., 2, 5, and 10\%) in Figures 2a, 2b, and $2 c$, respectively. It is possible that succinic esterified lignin has a dispersive effect on black spruce fibers but no observation could validate the hypothesis that esterified lignin is acting as a coupling agent. The possible effect of esterified lignin acting as dispersing agent could be verified through improvements in mechanical properties. For formulations containing MAPE (5 and 10\%), no interfacial void can be observed in Figures 2e and 2f, indicating strong interfacial adhesion. However, the formulation with only $2 \%$ MAPE has poor interface as observed in Figure 2d, just slightly better than succinic esterified lignin alone. These observations on MAPE reveal that a minimum content is necessary and the fact that no difference observed between $5 \%$ and $10 \%$ indicates that the optimal MAPE content is around 5\%. This value is consistent with the work of Mechraoui, Riedl, and Rodrigue (2007) for which the optimum coupling agent content was around $4 \%$ for a system composed of polypropylene and hemp fibers with maleated polypropylene as a coupling agent. In another system containing basalt fibers in HDPE (from recycled WPC), Chen et al. (2013) determined an optimal MAPE content of 5-8\%. Formulation containing 5\% maleic esterified Kraft lignin is presented in Figure $2 \mathrm{k}$, in which the interface looks slightly better than for formulations containing succinic acid esterified lignin, but not better than formulations containing $5 \%$ or $10 \%$ MAPE, and similar to the interface of formulation with $2 \%$ MAPE. To act as a coupling agent, esterified lignin needs to be attached to the black spruce bark fibers at the interface between fibers and matrix. This capacity of esterified lignin to be positioned between bark fibers and HDPE has been observed for maleic esterified lignin which was found to be positioned near black spruce fibers. The best interface was nevertheless obtained with 5\% MAPE (Figure 2e) and will be used as reference to discuss the next part of SEM observations.

\subsubsection{Combination of Esterified Kraft Lignin With MAPE as Coupling Agent}

The combinations of succinic esterified Kraft lignin:MAPE at 1\%:1\% and 2.5\%:2.5\% (Figures $2 \mathrm{~g}$ and $2 \mathrm{~h}$ ) have good interfaces similar to the actual reference obtained with 5\% of MAPE (Figure 2e). However, this type of composite formulation was found to have a less effective interface than for the level of 5\% MAPE: 5\% lignin (Figure 2i). Although succinic esterification may have a positive impact, with an optimal content, in producing esterified lignin acting as dispersant of the black spruce bark fibers and MAPE (enhancing the efficiency of this commercial coupling agent) and/or compatibilizing agent and thus improving the properties of WPC. Esterification with maleic anhydride on the other hand has good potential even without MAPE (Figure 2k), but the combination of Kraft lignin esterified with maleic anhydride with MAPE at the same level of $2.5 \%$ (Figure 2j) seems to produce the same interface aspect as the reference with 5\% MAPE alone. This could mean that maleic esterification has a higher potential as coupling agent when combined with MAPE than succinic anhydride alone. 

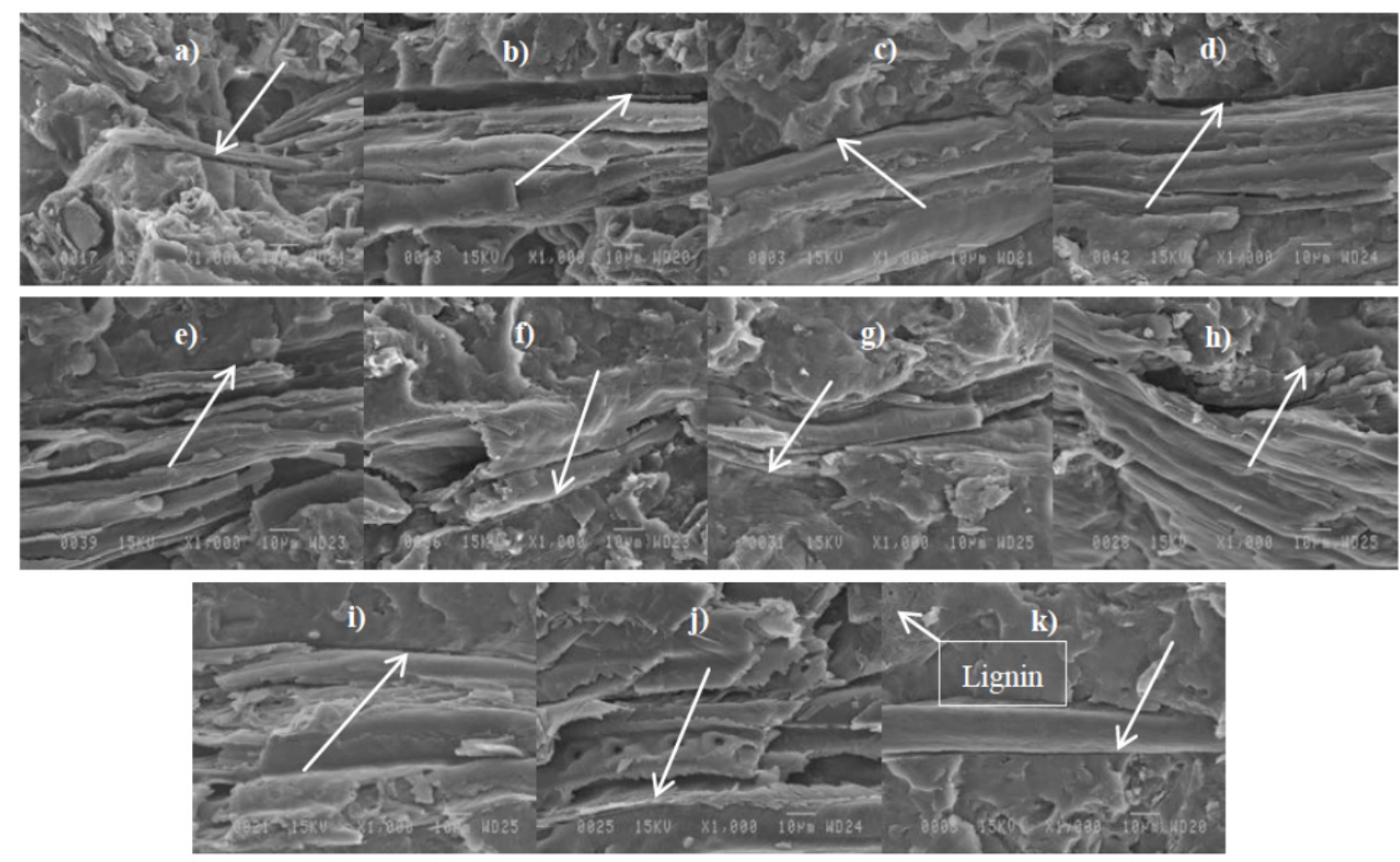

Figure 2. Scanning electron micrograph (SEM) of the WPC (letter a to k refer to the formulations described in Table 1)

\subsection{Crystallinity and Density}

The results of HDPE and WPC crystallinity obtained using DSC measurements, with a calculation based on the enthalpy of the tested WPC compared with a theoretical value of an HDPE crystal $(\Delta \mathrm{H}=293 \mathrm{~J} / \mathrm{g}$, as Wunderlich, 1973), are presented in Table 4. The obtained results reflect the importance of coupling agent and fibers contents. Sewda and Maiti (2007) found a linear decrease of crystallinity with increasing bark fibers content (Azadirachta indica) in HDPE formulations. At $26 \%$ bark content, they determined a crystallinity of $56 \%$ which is similar to the values determined here (between 45 and 55\%) at 30\% bark fibers. As for esterified Kraft lignin, crystallinity was determined to be maximum at $5 \%$ of succinic (or maleic) acid esterified lignin, alone or combined with MAPE. On the contrary, MAPE used as a sole coupling agent at $5 \%$ produced composites with the lowest crystallinity. There are situations where crystallinity may increase with the addition of contaminant (such as bark fibers or esterified lignin) which is adding nucleation points. However, if compatibility was not good, the crystals formed around the multiple nucleation points could be smaller than in the presence of a lower number of nucleation points having better compatibility. The use of $5 \%$ coupling agent seems again to be the optimum content in this context. One can hypothesise that higher crystallinity and better compatibility between bark fibers and HDPE may result in better mechanical properties, which was validated by the results presented in Table 4 . The density results are also presented in Table 4 . Higher density of the composites, compared to HDPE, is due to the presence of $30 \%$ fiber because HDPE has a density of $940 \mathrm{~kg} / \mathrm{m}^{3}$ (Table 4), while bark fibers density is 1557 $\mathrm{kg} / \mathrm{m}^{3}$ (Table 2) corresponding to the cell wall density as determined by pycnometry (Kellogg \& Wangaard, 1969; Zauer et al., 2013). These results can be related to mechanical properties because density has a positive impact on these properties, as can be seen from the results presented in Table 4. 
Table 4. Properties of black spruce refined bark

\begin{tabular}{|c|c|c|c|c|c|c|}
\hline \multirow[b]{2}{*}{ Coding } & \multirow[b]{2}{*}{$\begin{array}{l}\text { Crystallinity } \\
(\%)\end{array}$} & \multirow[b]{2}{*}{$\begin{array}{l}\text { Density } \\
\left(\mathrm{kg} / \mathrm{m}^{3}\right)\end{array}$} & \multirow{2}{*}{$\begin{array}{l}\text { Flexural properties } \\
\mathrm{MOE}^{1} \\
(\mathrm{MPa})\end{array}$} & \multicolumn{3}{|c|}{ Tensile properties } \\
\hline & & & & $\begin{array}{l}\mathrm{MOE}^{1} \\
(\mathrm{MPa})\end{array}$ & $\begin{array}{l}\text { Stress at break } \\
(\mathrm{MPa})\end{array}$ & $\begin{array}{l}\text { Strain at break } \\
(\%)\end{array}$ \\
\hline \multirow{2}{*}{$\mathrm{a}$} & 48.8 & 1049 & $1429^{B}$ & $423^{\mathrm{AB}}$ & $11.1^{\mathrm{C}}$ & $9.4^{\mathrm{EF}}$ \\
\hline & $(0.7)$ & (1) & $(50)$ & (20) & $(0.8)$ & $(0.8)$ \\
\hline \multirow{2}{*}{$\mathrm{b}$} & 54.6 & 1052 & $1473^{\mathrm{B}}$ & $403^{\mathrm{AB}}$ & $9.0^{\mathrm{C}}$ & $6.8^{\mathrm{F}}$ \\
\hline & $(0.8)$ & (2) & (37) & (31) & $(0.4)$ & $(0.4)$ \\
\hline \multirow{2}{*}{$\mathrm{c}$} & 47.0 & 1037 & $1547^{\mathrm{AB}}$ & $435^{\mathrm{AB}}$ & $9.8^{\mathrm{C}}$ & $9.7^{\mathrm{DE}}$ \\
\hline & $(0.7)$ & (2) & (20) & (33) & $(0.4)$ & $(0.9)$ \\
\hline \multirow{2}{*}{ d } & 55.4 & 1058 & $1449^{\mathrm{B}}$ & $396^{\mathrm{AB}}$ & $20.3^{\mathrm{A}}$ & $12.2^{\mathrm{CD}}$ \\
\hline & $(0.8)$ & (2) & (45) & (10) & $(0.8)$ & (1.6) \\
\hline \multirow{2}{*}{ e } & 47.9 & 1000 & $1551^{\mathrm{AB}}$ & $445^{\mathrm{A}}$ & $21.3^{\mathrm{AB}}$ & $12.1^{\mathrm{CD}}$ \\
\hline & $(0.7)$ & (2) & $(56)$ & (18) & $(1.2)$ & $(0.4)$ \\
\hline \multirow{2}{*}{$\mathrm{f}$} & 52.4 & 1008 & $1433^{\mathrm{B}}$ & $384^{\mathrm{AB}}$ & $21.4^{\mathrm{AB}}$ & $18.5^{\mathrm{A}}$ \\
\hline & $(0.8)$ & (1) & (106) & (21) & $(1.2)$ & $(1.1)$ \\
\hline \multirow{2}{*}{$\mathrm{g}$} & 52.8 & 1011 & $1545^{\mathrm{AB}}$ & $445^{\mathrm{A}}$ & $25.1^{\mathrm{A}}$ & $12.6^{\mathrm{C}}$ \\
\hline & $(0.8)$ & (1) & (56) & (10) & $(0.8)$ & $(0.6)$ \\
\hline \multirow{2}{*}{ h } & 56.5 & 1016 & $1614^{\mathrm{AB}}$ & $413^{\mathrm{AB}}$ & $22.3^{\mathrm{AB}}$ & $12.8^{\mathrm{C}}$ \\
\hline & $(0.8)$ & (1) & (41) & (14) & $(0.9)$ & $(0.9)$ \\
\hline \multirow{2}{*}{$\mathrm{i}$} & 46.6 & 1010 & $1530^{\mathrm{AB}}$ & $396^{\mathrm{AB}}$ & $23.0^{\mathrm{AB}}$ & $15.5^{\mathrm{B}}$ \\
\hline & $(0.7)$ & (1) & (54) & (14) & $(1.2)$ & $(0.8)$ \\
\hline \multirow{2}{*}{ j } & 55.6 & 1019 & $1618^{\mathrm{AB}}$ & $431^{\mathrm{AB}}$ & $22.4^{\mathrm{AB}}$ & $13.0^{\mathrm{BC}}$ \\
\hline & $(0.8)$ & (1) & (73) & (14) & (1.9) & $(0.8)$ \\
\hline \multirow{2}{*}{$\mathrm{k}$} & 51.6 & 1026 & $1667^{\mathrm{A}}$ & $370^{\mathrm{B}}$ & $11.2^{\mathrm{C}}$ & $8.9^{\mathrm{EF}}$ \\
\hline & $(0.8)$ & (1) & (60) & (26) & $(0.8)$ & $(0.6)$ \\
\hline \multirow{2}{*}{$\begin{array}{l}\text { Without } \\
C-A^{2}\end{array}$} & 47.5 & 1009 & 1495 & 434 & 19.3 & 10.5 \\
\hline & (0.6) & (1) & (18) & (11) & (0.6) & $(0.2)$ \\
\hline $100 \%$ & 40.2 & 940 & 1050 & 349 & 13.1 & 122.6 \\
\hline$H D P E$ & $(0.5)$ & (1) & (46) & (5) & $(0.1)$ & $(0.3)$ \\
\hline
\end{tabular}

1: $\overline{\mathrm{MOE}}=$ Modulus of elasticity; 2 : Without $\mathrm{C}-\mathrm{A}=$ without any coupling agent. Standard deviation is in brackets. For each property, values followed by the same letter are not significantly different and values followed by different letters are significantly different at 0.05 probability level (letter a to $\mathrm{k}$ refer to formulations given in Table 1).

\subsection{Mechanical Properties}

The results of flexural and tensile measurements are presented in Table 4. Flexural modulus (MOE) is in the range from 1400 to $1700 \mathrm{MPa}$ which represents a 30 to $60 \%$ improvement compared to neat HDPE (1050 MPa). Tensile MOE are in the range from 350 to $450 \mathrm{MPa}$ (350 MPa for HDPE), giving a maximum improvement of $30 \%$. Stresses at break are between 9 and $25 \mathrm{MPa}$ (13 MPa for HDPE) which corresponds to a maximum improvement of $90 \%$. This substantial increase indicates the clear effect of coupling agent addition. Finally, tensile strain at break values are in a range from 5 to $20 \%$ for WPC (125\% for HDPE) corresponding to a less elastic behavior of the material as expected. The determined mechanical properties are in the same range as those 
reported by Bouafif et al. (2009) for HDPE composites containing bark "fiber-like" particles, having a modulus of elasticity equal to $1,600 \mathrm{MPa}$, a tensile strength of $22 \mathrm{MPa}$ and a strain at break of $6.6 \%$. Similar results were obtained by Ngueho-Yemele et al. (2013) for WPC containing bark "fiber-like", with a flexural modulus of elasticity equal to $1,436 \mathrm{MPa}$, a tensile modulus of elasticity of 1,766 MPa (the only property much higher than here), a tensile strength of $10.6 \mathrm{MPa}$ and a strain at break of $2.8 \%$. The results of Table 4 are also slightly better than those reported for composites containing hemp fibers by Ramezani Kakroodi et al. (2013) having for 30\% of hemp a tensile modulus of elasticity of $340 \mathrm{MPa}$, a tensile strength of $15.3 \mathrm{MPa}$ and a strain at break of $17 \%$.

\subsubsection{Esterified Kraft Lignin as Coupling Agent}

Analyzing the flexural modulus results for formulations a, b and c (Tables 1 and 4), increasing succinic esterified lignin content had a positive influence on this property, but no difference was found in terms of tensile modulus and stress at break. Concerning strain at break, no clear tendencies were observed for the three WPC formulations studied. Composites using MAPE as coupling agent ( $\mathrm{d}$ to $\mathrm{f}$ ) have higher strain at break with increasing MAPE content, probably due to the intrinsic elasticity of this commercial coupling agent. Flexural modulus and tensile properties (modulus of elasticity and stress at break) of these formulations increased with increasing MAPE content, except for tensile modulus which increased until a MAPE content of 5\% was reached, after which tensile modulus decreased. This optimal coupling agent content, in term of mechanical properties, validates the previous SEM observation (Figure 2) in terms of better bark fiber-HDPE interface quality. This optimal MAPE content is also in agreement with Mechraoui et al. (2007) whose work established the best content near 4\% (based on fibers mass) and with Chen et al. (2013) with an optimal content of 5-8\% (based on fibers mass). To compare the best modification between succinic and maleic esterification, analysis of formulations $\mathrm{a}, \mathrm{b}, \mathrm{c}$ (for succinic esterification) and $\mathrm{k}$ (for maleic esterified lignin) was done via a Duncan test. This analysis proved that composites containing maleic anhydride esterified lignin had significantly higher modulus of elasticity $(+7.2 \%)$ than composites containing succinic modified lignin, but no statistical difference in terms of stress and strain at break (Table 4) could be determined. Further analysis of mechanical performance, with a simple calculation of the gain (in \%) of each property measured relative to the neat HDPE matrix (Table 5), indicates that no clear tendencies could be found for succinic esterification. However, the best Kraft lignin content for this type of modification was determined to be $10 \%$ (succinic esterified lignin content based on fiber mass), with increases of $25 \%$ and $47 \%$ for flexural and tensile modulus of elasticity respectively, but with losses of $25 \%$ on stress at break and $92 \%$ on strain at break. An optimum MAPE content was found to be $5 \%$ with improvements of $27 \%$ and $48 \%$ for flexural and tensile modulus, $63 \%$ stress at break, but a $90 \%$ loss on strain at break (less elastic material). Maleic esterified lignin alone had a limited effect on WPC properties since gains in terms of tensile properties were much lower: $6 \%$ increase for modulus of elasticity, with $14 \%$ stress at break and 93\% strain at break losses. The addition of maleic anhydride esterified lignin appears to be intermediate between succinic anhydride Kraft lignin and MAPE as coupling agents. Finally, maleic esterification of Kraft lignin had the best effect on flexural modulus of elasticity with an improvement of $59 \%$.

Table 5. Tensile and flexural properties gain (in \%) for WPC formulations using MAPE or esterified lignin alone

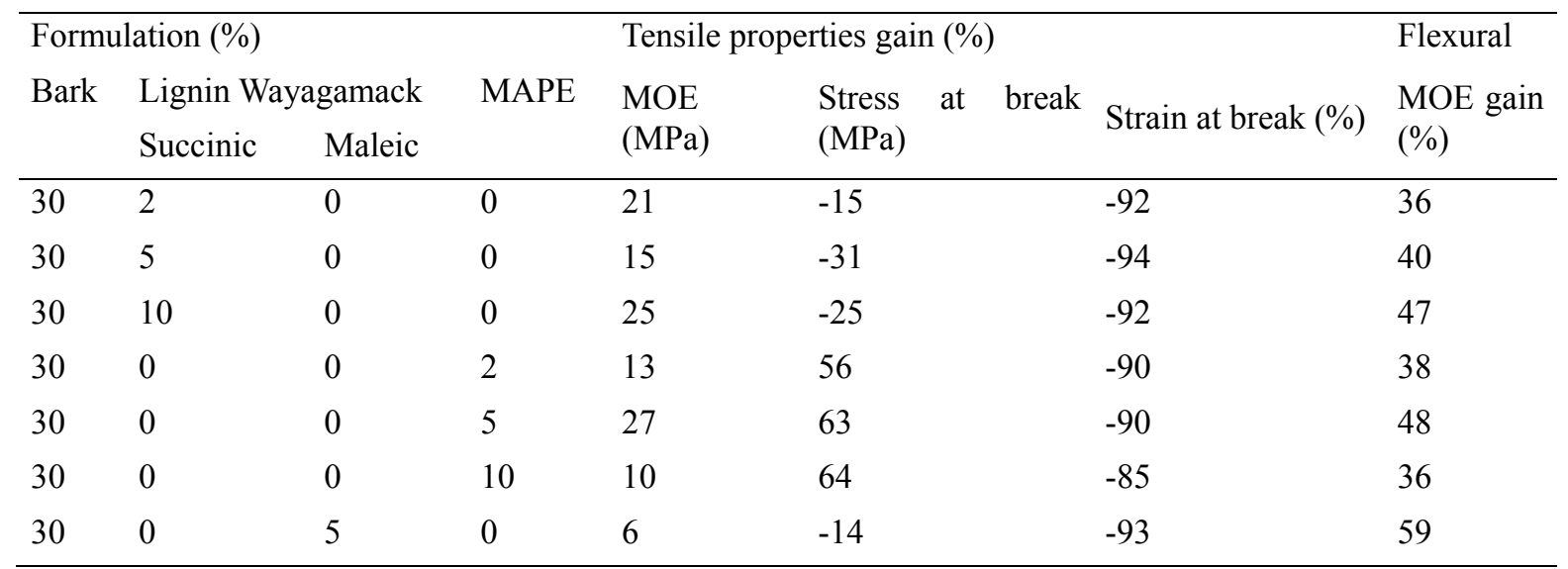

\subsubsection{Combination of Esterified Kraft Lignin With MAPE as Coupling Agent}

The combination of succinic esterified lignin with MAPE as coupling agent (formulations $g$ to i) confirmed the trends observed with MAPE alone, with the best properties obtained at a total coupling agent content of $5 \%$. The 
Duncan statistical test (Table 4) showed that the best coupling agent is to combine equal amounts of MAPE and maleic esterified lignin at $5 \%$ total which yields the best combination of flexural and tensile properties. Similar optimal coupling agent content was reported in the literature on WPC with other types of lignocellulosic fibers (Mechraoui et al., 2007; Chen et al., 2013). It is important to notice that the combination of MAPE with maleic esterified lignin produced WPC with better mechanical properties than using MAPE alone $(4.1 \%$ increase of flexural modulus of elasticity, $7.7 \%$ decrease of tensile modulus of elasticity, $4.9 \%$ increase in stress at break and an increase of $6.9 \%$ for strain at break). It seems that MAPE has a strong affinity towards HDPE, while modified lignin has good compatibility with native lignin from bark fibers, as maleic functions grafted on it recognize similar functions in MAPE thus creating a new combination of coupling agents. This result concerning the combination of MAPE and maleated Kraft lignin is corroborated by SEM observation because the interface of this formulation (Figure 2k) is very similar to the reference with 5\% MAPE (Figure 2e). The results of Bouafif, Koubaa, Perre, Cloutier, and Riedl (2008) indicated certain limitations of using MAPE as coupling agent with jack pine bark fibers (Pinus banksiana) in composites based on HDPE. Here, the addition of esterified (succinic and maleic) Kraft lignin in HDPE composites has proved to positively influence MAPE efficiency as a coupling agent and improved the interface between natural fibers (bark) and polyolefin matrix, perhaps due to the high porosity of esterified Kraft lignin (Figure $1 \mathrm{cl}$ ), which is offering space to create mechanical bonds with the matrix) and thus resulting in production of WPC with better mechanical properties. Using the calculations on gain in the studied properties of these formulations based on a combination of MAPE and esterified Kraft lignins and taking the WPC with optimal MAPE content $(5 \%)$ as reference, the obtained results made it possible to identify the best combination of MAPE and modified lignin (Table 6). Indeed, the combination of MAPE (1\%) with succinic Kraft lignin (1\%) produced composites with better properties than MAPE (5\%) alone: $+27 \%$ tensile modulus of elasticity, $+92 \%$ stress at break, $-90 \%$ strain at break, and $+47 \%$ flexural modulus. This combination is very favorable as it decreases considerably the content of synthetic coupling agent (MAPE) by a factor of five, while introducing natural polymer. As for the combination of maleated Kraft lignin $(2.5 \%)$ with MAPE $(2.5 \%)$, the tensile properties are similar to MAPE $(5 \%)$ alone with $+23 \%$ tensile modulus, $+71 \%$ stress at break and $-89 \%$ strain at break reducing by a half the MAPE content in WPC. However, this combination is the best solution to optimise also flexural modulus with an increase of $+54 \%$. The potential of application of esterified lignin combined with MAPE is based on two different mechanisms of action and has the advantage to offer sites for mechanical bonding to the matrix through the high porosity of esterified lignin. Succinic esterified Kraft lignin seems to act as a very efficient dispersant, improving the action of MAPE yielding the best formulation at $1 \%$ lignin: $1 \%$ MAPE, while maleic esterified Kraft lignin is forming a good interaction between the maleated parts of MAPE (grafted maleated function) with the esterified lignin part preserving its affinity towards bark fibers. Thus, a new coupling agent with an affinity to the matrix through MAPE and a good affinity to the fibers through the esterified Kraft lignin is created through the combination of MAPE with Kraft lignin esterified with maleic acid anhydride.

Table 6. Tensile and flexural properties gain (in \%) for WPC formulations using a combination of MAPE and esterified lignin. The first line is the best formulation from Table 5 (5\% MAPE)

\begin{tabular}{|c|c|c|c|c|c|c|c|c|}
\hline \multicolumn{4}{|c|}{ Formulation (\%) } & \multicolumn{4}{|c|}{ Tensile properties gain (\%) } & \multirow{3}{*}{$\begin{array}{l}\text { Flexural } \\
\text { MOE gain } \\
(\%)\end{array}$} \\
\hline \multirow[t]{2}{*}{ Bark } & \multicolumn{2}{|c|}{ Lignin Wayagamack } & \multirow[t]{2}{*}{ MAPE } & \multirow{2}{*}{$\begin{array}{l}\mathrm{MOE} \\
\text { (MPa) }\end{array}$} & \multirow{2}{*}{\multicolumn{2}{|c|}{$\begin{array}{l}\text { Stress } \\
(\mathrm{MPa})\end{array}$}} & \multirow{2}{*}{ Strain at break (\%) } & \\
\hline & Succinic & Maleic & & & & & & \\
\hline 30 & 0 & 0 & 5 & 27 & 63 & & -90 & 48 \\
\hline 30 & 1 & 0 & 1 & 27 & 92 & & -90 & 47 \\
\hline 30 & 2.5 & 0 & 2.5 & 18 & 71 & & -90 & 54 \\
\hline 30 & 5 & 0 & 5 & 13 & 76 & & -87 & 46 \\
\hline 30 & 0 & 2.5 & 2.5 & 23 & 71 & & -89 & 54 \\
\hline
\end{tabular}

\subsection{Statistical Analysis}

The results of the analysis of variance (ANOVA) are presented in Table 7 and show a significant effect of the interaction between the type of esterification (Typ) and the composition (Comp) of the formulations on tensile modulus at 0.05 probability level. No main effects are significant for tensile modulus. This interaction is illustrated in Figure 3 with the surface response helping to understand its influence on WPC. It can be assumed 
that it is due to the favorable presence of MAPE and of appropriate esterification to optimize the system. Furthermore, the micrographs and mechanical properties indicated the influence of the esterification method and the effectiveness of MAPE on the morphological structure of black spruce bark fibers-HDPE composites (Figure 2) and on WPC tensile modulus. Tensile stress at break, as shown in Table 7, reveals no significant interaction. But the main effect of coupling agent composition is significant at the 0.01 probability level. This result proves the potential of MAPE combined with esterified Kraft lignin, giving better properties to the composites. To conclude on tensile properties, the strain at break presented in Table 7 was examined and no significant interaction was found. The composition and content are significant at 0.01 probability level, allowing to confirm that the combination of MAPE with esterified lignin is a potential way to optimize bark/HDPE WPC. Nevertheless, an optimum coupling agent (or combination) content needs to be determined (for each composition) because it is highly significant for strain at break. Finally, the ANOVA analysis can be used to examine how the studied parameters influence the flexural modulus (Table 7). There were no statistically significant interactions determined by this analysis, and the main effect of esterification type (Typ) is the only significant factor at the 0.01 probability level. This result is contributing to new information about this novel type of coupling agent (esterified Kraft lignin) proving the potential of maleic esterification. This statistical analysis result was confirmed by SEM observations (Figure 2) and through mechanical properties previously discussed (Tables 4$6)$.

Table 7. ANOVA results (F-values) for tensile and flexural properties of bark/esterified lignin/HDPE WPC

\begin{tabular}{lllll}
\hline & \multicolumn{2}{l}{ Tensile properties } & & Flexural property \\
Source of variation & MOE (MPa) & Stress at break (MPa) & Strain at break (\%) & MOE (MPa) \\
\hline Main effect & & & \\
Type (Typ) & $0.63^{\mathrm{NS}}$ & $1.32^{\mathrm{NS}}$ & $2.19^{\mathrm{NS}}$ & $8.80^{* *}$ \\
Content (Cont) & $1.35^{\mathrm{NS}}$ & $0.31^{\mathrm{NS}}$ & $18.3^{* *}$ & $1.15^{\mathrm{NS}}$ \\
Composition (Comp) & $0.64^{\mathrm{NS}}$ & $93.6^{* *}$ & $28.4^{* *}$ & $1.29^{\mathrm{NS}}$ \\
\hline Interaction effect & & & \\
Typ*Comp & $4.83^{*}$ & $1.61^{\mathrm{NS}}$ & $0.53^{\mathrm{NS}}$ & $1.84^{\mathrm{NS}}$ \\
Cont*Comp & $1.46^{\mathrm{NS}}$ & $0.79^{\mathrm{NS}}$ & $2.28^{\mathrm{NS}}$ & $0.85^{\mathrm{NS}}$ \\
\hline NS $:$ & Not significant at 0.05 probability level & & \\
${ }^{*}:$ & Significant at 0.05 probability level & & \\
${ }^{* *}:$ & Significant at 0.01 probability level & &
\end{tabular}
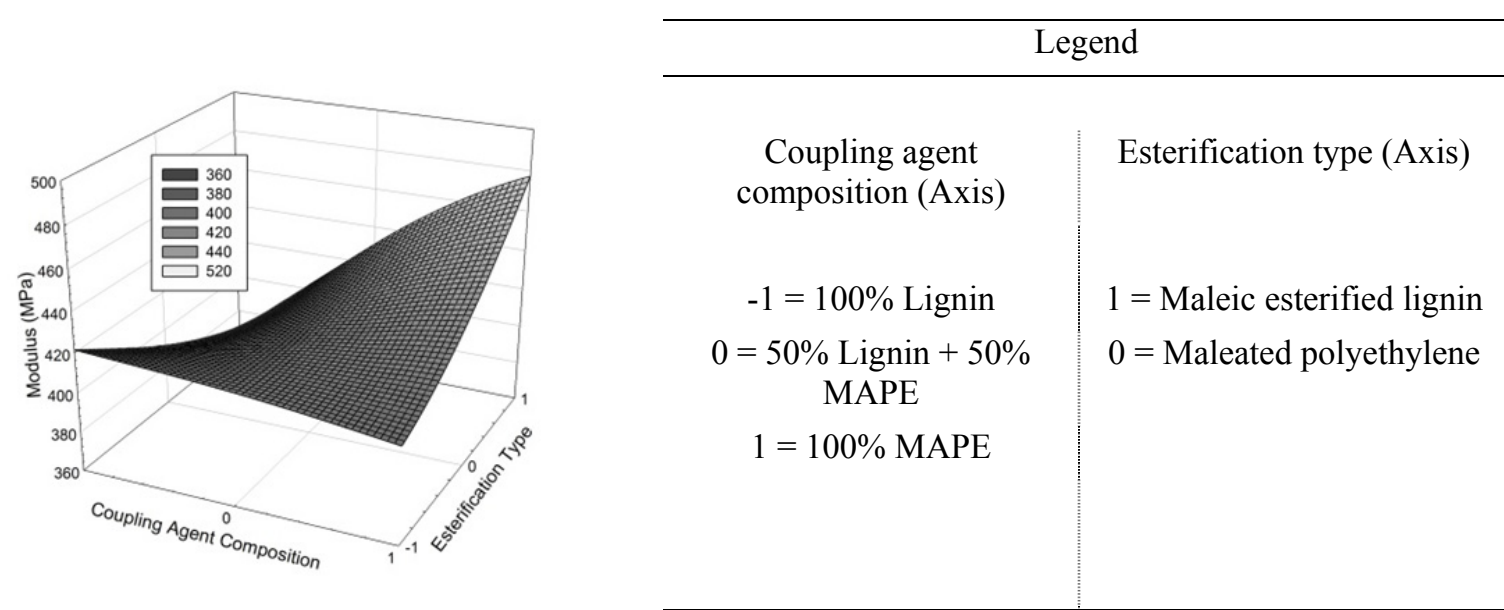

Figure 3. Surface response explaining the interactions observed in the statistical analysis: Tensile modulus (MPa) as a function of coupling agent composition and esterification type 


\section{Conclusions}

In this study, composites based on HDPE with refined black spruce bark fibers (30\% wt.) and coupling agents were produced. In particular, a novel way to improve compatibility between bark fibers and HDPE through the use of esterified Kraft lignins and a combination of these lignins with MAPE at equal amounts is presented. Since natural fibers contain lignin, lignin esterification created a structure which acted as a coupling agent between the hydrophobic HDPE matrix and hydrophilic bark fibers, while also improving compatibility by acting as a dispersing agent in combination with MAPE, due to partial similarity of chemical structures. The effect of coupling agent composition was determined to be highly significant on mechanical properties. The type of coupling agent (MAPE versus esterified lignin versus a mixture of them) was significant on flexural modulus, while coupling agent content $(2,5$, and $10 \%)$ was significant for tensile strain at break. Finally, coupling agent composition (MAPE:lignin ratio) was significant for stress at break. An interaction between coupling agent content and composition was significant on tensile modulus only. Each significant factor and the interaction give important knowledge which helped to understand how esterified Kraft lignin was acting inside the WPC. The statistical analysis of interactions between composition and type of lignin esterification made it possible to find the best parameters to optimize the mechanical properties of the composites. A combination of maleic anhydride esterified Kraft lignin with MAPE, at a level of 5\% total content (MAPE:esterified lignin of 2.5\%:2.5\%) allowed to reduce by half the use of commercial petrochemical coupling agent (MAPE), while succinic anhydride esterified Kraft lignin with MAPE, at a level of 2\% total content (MAPE:esterified lignin; 1\%:1\%) allowed to cut MAPE content by five while producing composites with better properties. These are important results since this research indicated the possibility of reducing the quantity of synthetic coupling agent (MAPE) and replacing it by esterified Kraft lignin while getting better mechanical results than MAPE alone. Keeping in mind these four refining principles used in this study:

- $30 \%$ of petrochemical matrix (HDPE) was replaced by black spruce bark fibers,

- Kraft lignin was obtained by precipitation from black liquor using $\mathrm{CO}_{2}$ produced inside this pulp and paper process,

- precipitated Kraft lignin was esterified and the results obtained in this study indicate that it can be used to replace half of the synthetic coupling agent MAPE, or even to reduce its quantity to one fifth,

- these new WPC can be used to produce energy at the end of their life cycle, since they are constituted almost entirely of $\mathrm{C}, \mathrm{H}$, and $\mathrm{O}$,

- the development of biosourced composites studied in this research is therefore incorporating several sustainable chemistry and engineering principles (Anastas \& Zimmerman, 2003).

\section{Acknowledgements}

The authors are grateful to the Fonds de Recherche du Québec - Nature et Technologies (FRQNT) for financial support. Kruger-Wayagamack for black liquor, and Diane Schorr for providing esterified Kraft lignins. Also, FPInnovations is acknowledged for bark fibers supply. Finally, Sylvain Auger, Yves Bédard, André Ferland, Yann Giroux, and David Lagueux are gratefully acknowledged for their technical support throughout this project.

\section{References}

Anastas, P. T., \& Zimmerman, J. B. (2003). Design through the Twelve Principles of Green Engineering. Environmental Science \& Technology, 37(5), 94-101. http://dx.doi.org/10.1021/es032373g

ASTM Standard D 1102. Standard Test Method for Ash in Wood.

ASTM Standard D 1106. Standard Test Method for Acid-Insoluble Lignin in Wood.

ASTM Standard D 1109. Standard Test Method for 1\% Sodium Hydroxide Solubility of Wood.

ASTM Standard D 1238. Standard Test Method for Melt Flow Rates of Thermoplastics by Extrusion Plastometer.

ASTM Standard D 638. Standard Test Method for Tensile Properties of Plastics.

ASTM Standard D 790. Standard Test Methods for Flexural Properties of Unreinforced and Reinforced Plastics and Electrical Insulating Materials.

Bouafif, H., Koubaa, A., Perré, P., \& Cloutier, A. (2009). Effects of fiber characteristics on the physical and mechanical properties of wood plastic composites. Composites Part A, 40(12), 1975-1981. http://dx.doi.org/10.1016/j.compositesa.2009.06.003 
Bouafif, H., Koubaa, A., Perre, P., Cloutier, A., \& Riedl, B. (2008). Analysis of Among-Species Variability in Wood Fiber Surface Using DRIFTS and XPS: Effects on Esterification Efficiency. Journal of Wood Chemistry and Technology, 28(4), 296-315. http://dx.doi.org/10.1080/02773810802485139

Browning, B. L. (1967). Methods of Wood Chemistry (Vol. 1-2). N.Y., USA: Interscience Publishers.

Chen, J. X., Wang, Y., Gu, C. L., Liu, J. X., Liu, Y. F., Li, M., \& Lu, Y. (2013). Enhancement of the Mechanical Properties of Basalt Fiber-Wood-Plastic Composites via Maleic Anhydride Grafted High-Density Polyethylene (MAPE) Addition. Materials, 6(6), 2483-2496. http://dx.doi.org/10.3390/ma6062483

Colom, X., Carrasco, F., Pagès, P., \& Cañavate, J. (2003). Effects of different treatments on the interface of HDPE/lignocellulosic fiber composites. Composites Science and Technology, 63(2), 161-169. http://dx.doi.org/10.1016/S0266-3538(02)00248-8

Fang, H., Deng, J., \& Zhang, T. (2010). Dilute acid pretreatment of black spruce using continuous steam explosion system. Applied Biochemistry and Biotechnology, 163(4), 547-557. http://dx.doi.org/10.1007/s12010-010-9061-6

FPInnovations \& Ressource Naturelle et faune du Québec. (2009). Guide de développement Le bioraffinage forestiers : possibilités pour les entreprises Québécoise de pâte et papier.

Gandini, A. (2008). Polymers from Renewable Resources: A Challenge for the Future of Macromolecular Materials. Macromolecules, 41(24), 9491-9504. http://dx.doi.org/10.1021/ma801735u

Gao, Z. H., Wang, X. M., Wan, H., \& Brunette, G. (2011). Binderless panels made with black spruce bark. BioResources, 6(4), 3960-3972.

García-Pérez, M. E., Royer, M., Desjardins, Y., Pouliot, R., \& Stevanovic, T. (2012). Picea mariana bark: A new source of trans-resveratrol and other bioactive polyphenols. Food Chemistry, 135, 1173-1182. http://dx.doi.org/10.1016/j.foodchem.2012.05.050

Gupta, G. K. (2009). Development of bark-based environmental-friendly composite panels. Master thesis. Faculty of Forestry, University of Toronto, Canada. 133p.

Kellogg, R. M., \& Wangaard, F. F. (1969). Variation in the cell-wall density of wood. Wood and Fiber Science, l(3), 180-204.

Lu, J., Wu, Q., \& McNabb, H. S. Jr. (2000). Chemical Coupling in Wood Fiber and Polymer Composites: A Review of Coupling Agents and Treatments. Wood and Fiber Science, 32(1), 88-104.

Manning, R., \& Tran, H. (2010). The carbon footprint of lime kilns: Part I Assessment of CO2 emissions. In: proceedings of TAPPI PEERS Conference, Norfolk, Virginia, United States, 16 to 19 October 2010.

Mechraoui, A., Riedl, B., \& Rodrigue, D. (2007). The effect of fiber and coupling agent content on the mechanical properties of hemp/polypropylene composites. Composite Interfaces, 14(7-9), 837-848. http://dx.doi.org/10.1163/156855407782106591

Ministère des ressources naturelles et de la faune du Québec (MRNF). (2007). Ressources et industries forestières - portrait statistique. Bilan des écorces. p. 506.

Nagy, M., Kosa, M., Theliander, H., \& Ragauskas, A. J. (2009). Characterization of $\mathrm{CO}_{2}$ precipitated Kraft lignin to promote its utilization. Green Chemistry, 12(1). 31-34. http://dx.doi.org/10.1039/B913602A

Ngueho-Yemele, M. C., Koubaa, A., Cloutier, A., Soulounganga, P., \& Wolcott, M. (2010). Effect of bark fiber content and size on the mechanical properties of bark/HDPE composites. Composites Part A, 41(1), 131-137. http://dx.doi.org/10.1016/j.compositesa.2009.06.005

Ngueho-Yemele, M. C., Koubaa, A., Cloutier, A., Soulounganga, P., Stevanovic, T., \& Wolcott, M. (2013). Effects of hot water treatment of raw bark, coupling agent, and lubricants on properties of bark/HDPE composites. Industrial Crops and Products, 42, 50-56. http://dx.doi.org/10.1016/j.indcrop.2012.05.012

Öhman, F., Theliander, H., Tomani, P., \& Axegard, P. (2006). Patent: Method for separating lignin from black liquor, LignoBoost. Sweden.

Ramezani Kakroodi, A., Kazemi, Y., \& Rodrigue, D. (2013). Mechanical, rheological, morphological and water absorption properties of maleated polyethylene/hemp composites: Effect of ground tire rubber addition. Composites Part B, 51(0), 337-344. http://dx.doi.org/10.1016/j.compositesb.2013.03.032

Schorr, D., Diouf, P. N., \& Stevanovic, T. (2013). Characterization and esterification of Kraft industrial lignins for biocomposite production. In: abstract \#1255 in section \#207 of 96th Canadian Chemistry Conference 
and exhibition, Quebec, Quebec, Canada, 26 to 30 May 2013.

Sewda, K., \& Maiti, S. N. (2007). Mechanical properties of HDPE/bark flour composites. Journal of Applied Polymer Science, 105(5), 2598-2604. http://dx.doi.org/10.1002/app.26293

Stevanovic, T. (2011). Chimie du bois, Protocoles de laboratoire, Faculté de Foresterie Géographie et Géomatique, Université Laval.

Stevanovic, T., \& Perrin, D. (2009). La chimie du bois (pp. 145-177). Presse Polytech. Universitaire et Romande.

Stevanovic, T., Rodrigue, D., Diouf, P., Schorr, D., \& Hu, L. (2012). Characterization of modified and non-modified industrial lignins for biocomposites production. In: proceedings of the 66th international convention of the Forest Products Society, Washington, DC, United States, 3 to 5 June 2012.

Tomani, P. (2009). The lignoboost process. Cellulose chemistry and technology, 44(1-3), 53-58.

Wallmo, H., \& Theliander, H. (2009). The influence of hemicelluloses during the precipitation of lignin in kraft black liquor. Nordic Pulp and Paper Research Journal, 24(2), 165-171. http://lup.lub.lu.se/record/1478138

Wunderlich, B. (1973). Macromolecular physics: Crystal structure, morphology, defects (Vol. 1, pp. 388-389). New York, NY: Academic Press.

Xing, C., Deng, J., \& Zhang, S. Y. (2007). Effect of thermo-mechanical refining on properties of MDF made from black spruce bark. Wood Science and Technology, 41(4), 329-338. http://dx.doi.org/10.1007/s00226-006-0108-3

Zauer, M., Pfriem, A., \& Wagenführ, A. (2013). Toward improved understanding of the cell-wall density and porosity of wood determined by gas pycnometry. Wood Sciences and Technologies, 47, 1197-1211 http://dx.doi.org/10.1007/s00226-013-0568-1

\section{Copyrights}

Copyright for this article is retained by the author(s), with first publication rights granted to the journal.

This is an open-access article distributed under the terms and conditions of the Creative Commons Attribution license (http://creativecommons.org/licenses/by/3.0/). 